\title{
LA SUPREMACÍA PRÁCTICA DE LOS DERECHOS HUMANOS. OPTIMISMO, PESIMISMO Y MODERACIÓN ${ }^{l}$
}

\author{
THE PRACTICAL SUPREMACY OF HUMAN RIGHTS. OPTMISM, \\ PESSIMISM AND MODERATION
}

\author{
GUILLERMO LARIGUET ${ }^{2}$ \\ (Universidad Nacional de Córdoba, Argentina) \\ RENÉ GONZÁLEZ DE LA VEGA ${ }^{3}$ \\ (Universidad Nacional Autónoma de México, México)
}

\begin{abstract}
RESUMEN
En este trabajo reflexionamos sobre la tesis normativa según la cual los derechos humanos tienen supremacía práctica sobre cualquier otra pieza de nuestro razonamiento moral, político o jurídico. Para esta reflexión indenticamos dos aproximaciones filosóficas divergentes. Una que denominamos "optimismo" que confía en las potencias poderosas de los derechos humanos para imponerse a cualquier otro argumento y para garantizar respuestas correctas a los conflictos prácticos. La otra aproximación, que denominamos "pesimista", tiene diversas variantes. Aquí nos detenemos en aquella postura que enfatiza en el grado de conflictividad cuasi irresoluble que plantean aparentemente muchos casos prácticos. Creeemos que ambas aproximaciones tienen un grano de verdad, pero ambas, sin embargo, conducen a un dilema teórico. Si aceptamos las premisas de una, debemos descartar las de la otra. Proponemos una postura intermedia o moderada que, mediante una suerte de equilibrio reflexivo, intenta adoptar los puntos más satisfactorios de ambas aproximaciones extremas.
\end{abstract}

Palabras-clave: Derechos humanos. Supremacía práctica. Optimismo. Pesimismo. Moderación

\begin{abstract}
In this paper we reflect about the normative view that human rights have practical supremacy over any other piece of our moral, political or legal reasoning. As regard this purpose we reflect on two divergent philosophical approaches. One we call "optimism" that relies on mighty powers of human rights in order to ensure correct answers to practical conflicts. The other approach, which we call "pessimistic" has several variants. Here we identify the position that emphasizes in some apparently unsolvable conflicts. We believe that both approaches have a grain of truth, but both, however, lead to a theoretical dilemma. If we accept the premises of one of both, we must discard the other. And the same is truth in the contrary sense. We propose an intermediate or moderate position that proposes a kind of reflective equilibrium between the two described positions above. In addition we try to adopt a more purified position with power to solve problems erased by the optimistic and pessimistic approaches.
\end{abstract}

Keywords: Human rights. Supremacy practice. Optimism. Pessimism. Moderation. 


\section{Introducción}

No toda crítica a los derechos humanos es una crítica a su existencia factual ni a su valor moral intrínseco. La crítica que tenemos en mente aún sostiene la objetividad del valor moral de los derechos humanos y tan sólo pretende repensar las estructuras básicas del pensamiento liberal moderno sin que eso implique adoptar una postura anti-liberal o sumergirse en las turbias e inciertas aguas del posmodernismo.

En las páginas que siguen nos dedicaremos a revisar críticamente los criterios de fundamentación o justificación que principalmente los liberales ilustrados han atribuido a los derechos humanos. Nuestro propósito es concentrarnos en una concepción bastante generalizada y robusta de tales derechos. Esta concepción responde a los presupuestos teóricos que fueron heredados por la filosofía de la Ilustración. Tal concepción postula que los derechos son herramientas normativas a través de las cuales podemos resolver "correctamente" todas las controversias jurídico-políticas y ético-políticas que surgen en las sociedades contemporáneas. Por "resolución correcta" entendemos la existencia de una solución que, frente a un conflicto entre derechos humanos, tiene el mérito de no sacrificar ningún valor o principio sustantivo. Es decir, que la solución no deja "pérdida moral". Repetimos la idea: los derechos humanos se entienden como una clase especial de herramientas normativas que sirven a los jueces (y a los operadores del derecho en general) para resolver "correctamente" cualquier clase de dificultad práctica. Repárese, además, en que cuando los filósofos que adoptan esta concepción de los derechos usan el término “correctamente" están pensando en una corrección de tipo moral y no, únicamente, en una corrección puramente jurídica o instrumental. Además suponen que la solución a un conflicto tiene la virtud de mostrar un cuadro coherente entre distintos principios o valores sustantivos que estaban en aparente conflicto o tensión. El corolario de esta forma de pensar se expresa en la tesis de la "supremacía práctica" de los derechos humanos; tesis cuyo contenido conceptual se clarificará cuando distingamos -más adelante- dos posturas diferentes sobre el alcance de los derechos humanos. Los especialistas en filosofía práctica sabrán que este tema ha suscitado una intensa discusión en la filosofía moral, jurídica y política contemporáneas. Desafortunadamente, y por razones de espacio, no podremos ocuparnos aquí de todos los problemas y argumentos que se han dado en torno a la tesis de la "supremacía práctica de los derechos humanos". Más bien, lo que nos proponemos hacer es presentar los argumentos desde dos perspectivas radicalmente distintas: la de los defensores y la de los detractores de la 
supremacía práctica de los derechos humanos. La primera ve en los derechos humanos un modelo que ha logrado configurar en la realidad del mundo un ideal normativo que es capaz de proveer con respuestas correctas a todos los problemas prácticos que nos acosan o pueden acosar. La segunda, en cambio, tiene dos vertientes: una robusta que ve a los derechos humanos como un sistema en crisis, un modelo que a lo sumo ha logrado entablar un teatro político-moral en el que los individuos se han propuesto jugar un papel de entusiastas, el cual lleva inevitablemente a una ceguera sobre la terrible realidad que nos rodea: una vida llena de problemas prácticos irresolubles, trágicos o dilemáticos frente a los que los derechos humanos no dan respuestas o las respuestas que dan son insatisfactorias y, otra, menos fuerte, que ve a en las teorías basadas en los derechos humanos un reduccionismo teórico que las ciega antes otras áreas de la moral sumamente importantes para afrontar y resolver ciertos problemas prácticos.

En primer lugar vamos a partir de las proposiciones de aquellos que defienden la tesis de la supremacía práctica de los derechos humanos, explicando la concepción de los derechos que ellos defienden. Para este fin, presentaremos de un modo amplio las tesis centrales de esta postura teórica a la que denominaremos (por razones que más tarde explicaremos) la perspectiva optimista de los derechos humanos. A continuación haremos lo mismo con la postura opuesta, la que denominaremos la perspectiva pesimista de los derechos humanos. A grandes rasgos, la tesis que sostendremos es que las dos posturas tienen algo de verdad. A los fines de nuestra argumentación vamos a admitir que es plausible la tesis optimista según la cual los derechos tienen una relevancia normativa innegable. Pero también vamos a suponer, en sintonía con la tesis pesimista, que hay algo de razón en que no siempre es posible o viable desde un punto fáctico, contextual o concreto mantener in toto la armonía entre los derechos que están en conflicto.

Ahora bien, el problema que encontramos es que ambas posturas, la optimista y la pesimista, al ser tan extremas terminan resultando mutuamente excluyentes. Esto nos sitúa en una especie de dilema teórico en el que si aceptamos las premisas de la una, tendremos que desechar las premisas de la otra. A efectos de escapar a este dilema, vamos a bosquejar una postura "intermedia" entre el optimismo y el pesimismo que nos permita rescatar de ambos extremos aquellas intuiciones filosóficas que nos parecen más plausibles, articulándolas en una tercera posición en la que puedan convivir juntas. Esta postura intermedia será denominada "moderada" y podría ser vista como una forma aristotélica de mesótes. Para no mantener un irritante suspenso sobre las tesis que acompañarán nuestra postura vamos a 
mencionarlas ahora, para luego regresar a ellas y analizarlas con cierto detenimiento. Éstas son las siguientes:

a) Como postulado a priori vamos a sostener que los derechos humanos son piezas maestras de logros de una reflexión moral madura. La naturaleza última de los derechos humanos es el resultado de una comprensión creciente y madura de moralidad; en especial de moralidad política. Esto sea dicho con la salvedad de que admitimos que los derechos positivizados a niveles constitucionales presuponen una complejidad sistémica mayor. La incorporación de derechos a materiales jurídicos exige, algo que no haremos aquí, una consideración pormenorizada de cómo inciden en el razonamiento práctico, por ejemplo de operadores del derecho como los jueces, la dimensión institucional del derecho y su naturaleza autoritativa. A esto se añade otro dato de enorme complejidad y dinamismo en el que no nos inmiscuiremos aquí y que tiene que ver con la internacionalización de los derechos humanos. Una reflexión de un Law of People y sus complejos mecanismos, aún en discusión y cambio, requieren desde luego un ensayo independiente y específico.

b) Que los derechos humanos, qua piezas morales, se integran, en nuestra perspectiva, a una versión del razonamiento práctico unitaria y no fragmentaria. Esto no significa moralizar cualquier dominio práctico porque sí. El riesgo de esto sería lo que se ha popularizado con el nombre de un "infierno moral". 5 Al contrario, en nuestra visión, el razonamiento práctico orbita sobre distintos dominios prácticos (estéticos, religiosos, políticos, jurídicos) lo cual no significa diluir los criterios de identidad y solución de conflictos de cada dominio. Antes bien, la idea de que la razón práctica se integra por distintos dominios y que no todos son de índole moral, que estos dominios son, por ejemplo, el estético o el religioso, convalida tácitamente el reconocimiento de una relativa autonomía de dichos dominios. Esta autonomía relativa implica que si hubiera un conflicto, digamos, a nivel de normas estéticas, el propio dominio contaría, en principio, con criterios de solución. Distinto es el caso si el conflicto estético tiene un punto de contacto fuerte y evidente con el dominio moral; porque, en dicho caso, por razones pre-asumidas de unidad del razonamiento práctico, deberían aplicarse criterios morales.

c) Que entre los derechos humanos y otras piezas normativas, por ejemplo objetivos colectivos o prudenciales, tienen primacía prima facie los derechos. Para revertir la prioridad, son necesarios fuertes argumentos políticos y éticos que justifiquen un sacrificio razonable y temporalmente delimitado de los derechos. 
d) Que entre los propios derechos humanos puede haber conflictos. Como partimos de la idea a priori de que tales derechos gozan de mismo rango axiológico, entonces estamos frente a un dilema moral.

e) Sostendremos que los dilemas morales no pueden evitarnos a priori lo que pragmatistas como Dewey denominaban una investigación racional. Los pasos de dicha investigación deberían conducir a bucear imaginativamente en un elenco de respuestas que cuenten como racionalmente aceptables. Las mismas, por orden de plausibilidad, irían en el siguiente orden. En primer lugar se debería tratar de escapar entre los cuernos del dilema, buscando satisfacer conjuntamente ambos derechos, lo cual podría requerir, a veces, y cuando ello resultara posible, en una satisfacción de compromiso entre ambos derechos. En segundo lugar, si lo anterior no fuera posible, buscar una solución lo menos lesiva posible para los derechos involucrados, minimizando los males. En tercer lugar, si un sacrificio irreparable fuese inevitable, entonces generar compromisos para mejorar a futuro nuestras creencias, prácticas o instituciones a fin de evitar o morigerar el impacto de conflictos futuros.

\section{La perspectiva optimista de los derechos humanos}

En los últimos cuarenta o cincuenta años, un amplio grupo de filósofos se ha encargado de ensalzar y robustecer los atributos prácticos que pueden llegar a tener los derechos humanos en el ámbito político-jurídico. Por ejemplo, Carlos Nino les atribuye varios dones: por un lado, dota a los derechos humanos de una capacidad inmanente de proveer corrección moral a todas las decisiones jurídicas, independientemente de si éstas explícitamente expresan su compromiso frente a esta clase de derechos. Por el otro, considera a los derechos humanos como criterios normativos idóneos para subsanar las indeterminaciones que sufren los sistemas jurídicos debido a lagunas, contradicciones, ambigüedades o imprecisiones lingüísticas. (Nino, 2005, p. 21 y ss).

Francisco Laporta (1987, p. 39), quien no es un defensor tan recio como lo sería Nino, en su texto Sobre el concepto de los derechos humanos, defiende que los derechos humanos acarrean un tipo de exigencias "morales" que suelen considerarse -por definicióncomo un tipo de exigencias últimas respecto de otros tipos de exigencias, como serían las de la prudencia o las mismas exigencias jurídicas. Dado que tienen carácter último -a lo cual habría que añadir el predicado "definitivo"- respecto de otro tipo de consideraciones prácticas, 
los derechos humanos gozan de lo que llamamos al principio del trabajo "supremacía práctica".

Por su parte, James Griffin (2008, p. 65) sostiene algo epistémicamente fuerte pero bastante usual entre los defensores de las teorías morales basadas en derechos, y es una equiparación absoluta entre el sistema de derechos y una concepción de la justicia. Griffin dice que "si el sistema de derechos humanos no abarcara por completo el dominio de la justicia, entonces, podríamos encontrar conflictos prácticos entre derechos y criterios de justicia [...] esta situación sería completamente embarazosa para el sistema de derechos humanos".

Para Manuel Atienza (2008, p. 149) , los derechos humanos marcan los límites dentro de los cuales puede moverse la reflexión ética y política. La "ideología” de los derechos humanos cumple -en ese sentido-una función análoga a la que cumplía la religión católica en la Europa medieval. "Los derechos humanos se han convertido, en cierto grado, en el banco de pruebas para cualquier teoría de la justicia: la validez o aceptabilidad de las mismas está en función de su grado de compromiso en la defensa de los derechos humanos $[\ldots] " .6$

Y claro, sin duda la propuesta teórica que mejor se ajusta a la perspectiva optimista de los derechos es la de Ronald Dworkin. Como ya es suficientemente sabido, una de las tesis que Dworkin ( 2002, p.397) defiende es que todo caso difícil en el derecho puede resolverse "correctamente" siempre y cuando los jueces presten atención a lo que dicen las normas del sistema: El derecho no se inventa, se descubre. Dworkin está convencido de que si aceptamos esta concepción de los derechos necesariamente tenemos que aceptar su tesis de la "única respuesta correcta en el derecho". ${ }^{7}$ Esta perspectiva se refuerza en su último libro (2011, pp. 351-364) en el que defiende que la concepción de los "erizos", menos popular que la de los zorros, pero más sólida, ve a los derechos como formando un todo armónico o coherente. Ahora bien, si prestamos atención, para esta clase de filósofos los derechos humanos funcionan, entre otras cosas, como: 1) reparadores de fallas, lagunas e indeterminaciones normativas, 2) como criterios últimos de justificación de las decisiones jurídicas, 3) como definición general de la justicia, 4) como límite infranqueable de las decisiones mayoritarias; 4) como un cuadro coherente en el que es posible alcanzar siempre respuestas correctas sin sacrificar ninguna de las demandas de los derechos que están en aparente conflicto. Es claro que en esta perspectiva la noción de "derecho humano" está prácticamente en el centro de 
cualquier argumento que merezca ser discutido con relación a la justicia, la bondad y la corrección moral de cualquier posición sustantiva en filosofía práctica.

¿Cuáles son las proposiciones teóricas de las que parten los optimistas para sostener que los derechos humanos pueden servir para hacer todo esto? Vamos a argumentar que la concepción optimista se apega al mismo ideal defendido filósofos ilustrados como Kant, Rousseau, Montesquieu, Voltaire, etc. (Todorov, 1999) En ese sentido su culto es a la Razón con mayúsculas (nihil est sine ratione) y creen que las luces que ésta nos presta son suficientes para solucionar correctamente cualquier clase de conflicto práctico. En este sentido, los optimistas son los que defienden una tesis racionalista o 'ultra' racionalista de los derechos. En otras palabras, son filósofos que no creen en la existencia de "casos límite" a la racionalidad práctica. Las proposiciones que les aseguran una perspectiva como esta son los tres pilares sobre los que se fundó el pensamiento ilustrado:

1. La primera de ellas consiste en que cualquier pregunta genuina puede ser contestada. Si una pregunta no encuentra respuesta se debe a que no es una pregunta genuina; bien formulada. Ante las preguntas genuinas, es posible que nosotros no conozcamos la respuesta, pero, podemos estar seguros de que alguien más la encontrará. Esta tesis la podríamos denominar como la tesis de la única respuesta correcta. ${ }^{8}$

2. La segunda proposición es que todas las respuestas son cognoscibles. Todas pueden ser descubiertas mediante medios que pueden ser trasmitidos y enseñados a cualquier persona. Esta proposición sostiene la existencia de métodos y de técnicas que nos aportan medios para descubrir en qué consiste el mundo y conocer nuestro lugar dentro de él. Un método que nos aporta el medio según el cual podemos alcanzar las respuestas correctas a todas las preguntas genuinas. A esta proposición la podríamos denominar como la tesis del método racional.

3. La tercera y última proposición consiste en que todas las respuestas que se den a preguntas genuinas deberán ser compatibles entre sí mismas. Si no son compatibles entre sí, el resultado sería el caos. Es una verdad lógica que una proposición verdadera no puede contradecir a otra proposición verdadera, por lo tanto, una respuesta correcta a una pregunta genuina no puede contradecir a otra respuesta correcta. Esta proposición la podemos denominar como la Tesis de la armonía de los valores.(Berlin, 1999, pp. 21-22)

En términos de los derechos humanos, la tesis optimista defiende entonces que: 
a) El sistema de derechos humanos es la representación moral, jurídica y política de la armonía de los valores (por ejemplo, el teórico hegeliano Brudner, 2007, p. 297 y ss). Los derechos han traído coherencia y consistencia a los modernos sistemas jurídicos. Ellos representan la gran pieza del rompecabezas normativo que terminará con las decisiones “intuitivas" o "discrecionales", por un lado, y con las decisiones "arbitrarias" o "populistas", por el otro. Todas las decisiones jurídicas y políticas, si pretenden corrección, deberán encontrarse en perfecta armonía con el catalogo de derechos. Una decisión que vulnere o violente algún derecho no es una decisión que pueda considerarse justificada correctamente. Por lo tanto, nuestro optimista es un optimista en cuanto al sistema de los derechos humanos.

b) El optimista también considera que debido a la tesis de la armonía, todas las decisiones jurídicas y políticas pueden contar con una respuesta correcta. Si las decisiones se basan en la estructura y contenido de los derechos humanos, las respuestas deberán ser correctas. Cada caso tiene una sola respuesta correcta. Es una verdad lógica que no pueden existir dos respuestas verdaderas y contradictorias a un mismo problema práctico. En este caso nuestro optimista defiende un optimismo en cuanto a la práctica ético-normativa.

c) Por último, el optimista sostiene que lo único que se requiere es encontrar en método adecuado de racionalidad. A este respecto, recuérdese, por caso, las tesis de la ponderación y el balanceo, tan famosas en la teoría del derecho merced a la obra de filósofos del derecho como Robert Alexy (2003); tesis que, como se sabrá, fueron elaboradas con el propósito de intentar garantizar la armonía y las respuestas correctas para conflictos entre principios. El hecho de que aun no hayamos perfeccionado este método, no quiere decir que no exista dicha armonía ni que no sea verdadera la tesis de la respuesta correcta. Por lo tanto, nuestro optimista es, también, un optimista en cuanto a nuestras capacidades epistémicas.

Puestas así las cosas, entonces el optimista considera que no hay reto práctico que los derechos humanos no puedan contestar adecuadamente. El optimismo, entonces, es una concepción que defiende la idea según la cual a través de los derechos humanos, encontraremos respuestas correctas a los conflictos prácticos más angustiantes de las sociedades modernas: desde el hambre, la educación, hasta problemas ético-individuales y jurídico relevantes: como el aborto, la eutanasia, el consumo de drogas y muchos más. El colofón de esta forma de pensar puede resumirse en estas tres ideas: 1) la primera dice que todos los conflictos normativos tienen respuesta; 2) La segunda dice que los derechos son una fuente normativa privilegiada o preferencial frente a otras demandas prácticas que provee de respuestas correctas a todos los conflictos normativos y, 3) la tercera dice que no hay 
conflictos normativos trágicos entre derechos porque estos constituyen un sistema armónico de valores. Esta concepción se inscribe dentro de una concepción más amplia de la capacidad poderosa de la razón práctica para solucionar correctamente todo tipo de conflicto normativo. Tal concepción responde a la idea ilustrada de que los individuos somos capaces de construir una sociedad ideal basada en el conocimiento de leyes objetivas que pueden ser aplicadas por técnicas racionales las cuales no dejan lugar a contradicciones ni incoherencias. En ese sentido, para estos filósofos los derechos humanos son la primavera del ideal de dominio universal de la razón.

\section{Pesimismo frente a la supremacía práctica de los derechos humanos.}

Ciertamente, la historia de los derechos humanos no siempre ha sido tersa, ni los filósofos siempre han sido optimistas con relación a sus capacidades prácticas ni en cuanto a su valor moral. Podemos encontrar muchos filósofos que no han abrazado el ideal de los derechos humanos. Las razones para cuestionar a los derechos pueden obedecer a distintas fuentes. Por caso, pensemos en algunos filósofos utilitaristas que han descreído de que la categoría "derechos humanos", en tanto "derechos morales" sea inteligible, en los pensadores de corte marxista que han pensado que bajo esta categoría súper-estructural se esconden resortes de poder económico no confesados, en aquellos que pertenecen a derroteros posmodernistas que alegan la idea de que los derechos humanos forma parte de mitos o grandes relatos en extinción e, incluso, varios que asumen una moral aristotélico-tomista que desconfía de la coherencia del discurso de los derechos humanos, como es el caso de MacIntyre (1987).

Situémonos por un momento en los filósofos de corte utilitarista. Piénsese, por ejemplo, en filósofos como Jeremy Bentham. Son sumamente famosas las palabras que este jurista y filósofo plasmó en sus Anarchical Fallacies cuando calificó a las doctrinas sobre los derechos naturales que habían inspirado a las constituciones americana y francesa. Bentham, como recuerda Hart (1983, p. 182) decía que: "la doctrina de los derechos naturales es en parte un sinsentido, y en parte peligrosamente anárquica, pues termina por homologar a los buenos y a los malos gobiernos. La doctrina es un 'berrido vertido en papel', no sólo es un sinsentido, sino que es un 'sinsentido subido en zancos"." 9 
A veces las razones para poner en cuestión la asunción lisa y llana de derechos humanos no ha tenido que ver con un empacho utilitarista o con resquemores marxistas, posmodernos o procedentes de alguna variante interpretativa de la ética arisotélico-tomista. Por caso, Joseph Raz (1986, pp. 193-194), sin la diatriba de Bentham, ni con argumentos utilitaristas, marxistas, posmodernistas, ni mucho menos tomistas, pone en cuestión la idea de que exista una teoría moral que esté únicamente basada en la noción de derechos individuales, tal como por ejemplo ha sido argumentado por filósofos como Ronald Dworkin en Taking Rights Seriously, o J. L. Mackie en Can There be a Right-Based Moral Theory? La idea que propone Raz es que cualquier teoría moral si aspira a ser válida o correcta debe estar sustentada en un principio más amplio y general como es el «principio humanístico». Este principio no es en sí mismo una teoría moral, sino una condición necesaria para la aceptabilidad de cualquier teoría moral. Esto es, un criterio último en el que todas las teorías morales deben descansar.

Ahora bien, ¿qué tipo de pesimismo defienden aquellos que no atribuyen a los derechos humanos los dones que le reconocen los optimistas? De toda la amplia gama de razones para rechazar o poner en duda la supremacía práctica de los derechos, aquí nos contentaremos con centrarnos en una en particular. Esta razón se vincula con la idea de "conflicto trágico", esto es, un conflicto donde cualquier salida es penosa, inevitablemente mala, e inclusive de espectro destructivo. Acudamos, por lo pronto, a un ejemplo tomado de la literatura ${ }^{10}$. Nos detengamos brevemente en un escritor español como Pío Baroja, usualmente considerado un "pesimista" (Rogers, 1962, p. 671) de una estirpe no muy diferente a la de Miguel de Unamuno.

En efecto, en la obra Paradox, Rey, Baroja nos ofrece un reclamo amargo sobre la civilización occidental. Paradox, y sus compañeros (una minoría selecta que guía a los "hombres-masa" hacia un sistema ideal) quedan vencidos por las tropas francesas que queman, matan, pervierten a los habitantes y los inficionan con sus enfermedades, todo ello, en nombre de la civilización. Aquí, Baroja no encuentra remedio ni salida. Cualquier solución que adopte Paradox, resultará contraproducente para su pueblo y para su ideal de civilización.

Frente a un panorama sombrío semejante, se encuentra la Antígona de Sófocles, cuando no parece posible determinar cuáles leyes obedecer: si las leyes positivas del Rey de Tebas, Creonte, u obedecer los mandatos divinos y dar digna sepultura a su hermano (Eskridge y Levinson, 1998, pp. 248-256) Este también es el mismo pesimismo que absorbe 
al Capitán Vere del cuento Billy Budd de Herman Melville cuando se encuentra en el dilema de si debe condenar a Billy Budd a muerte, como dictan las leyes marítimas, o si debe perdonarle la vida y no obedecer los mandatos del derecho y exponerse, en consecuencia, a un motín dentro en su barco (Post, 1998, pp. 217-225).

Las anteriores citas literarias pintan con detalle la sustancia del espíritu pesimista. Lo que los pesimistas aducen es que la vida no es un "noble sueño", para usar la conocida expresión de Hart (2001, p. 132 y ss). Sino que en el mundo, los individuos nos vemos en ocasiones sometidos a situaciones que podrían clasificarse como verdaderas encerronas morales de las cuales no podemos salir sin que esto implique una pérdida o un sacrificio moral.

Como ya anticipamos, en la literatura filosófica especializada a esta clase de conflictos comúnmente se les denomina dilemas morales o conflictos trágicos (Williams, 1993, p. 93). En este trabajo sostendremos que los dilemas morales o los conflictos trágicos consisten en las cuatro siguientes características conceptuales:

1) La primera de ellas es que son situaciones en la que un agente $S$ tiene la obligación moral de hacer $A$ y tiene la obligación moral de hacer $B$ pero no puede cumplir con ambas obligaciones al mismo tiempo, ya sea porque $B$ implica, precisamente, el no hacer $A$ o ya sea porque las circunstancias fácticas en las que se encuentra le impiden realizar ambas obligaciones conjuntamente (McConnell, 2010).

2) El conflicto no tiene resolución racional posible, por ejemplo, porque los valores o principios en conflicto son considerados como mutuamente inderrotables (1988, p. 20 y ss) o incomparables (Chang, 1997) o;

3) El conflicto podría ser resuelto eligiendo uno de los principios en pugna, pero esta elección entrañaría un lamentable sacrificio o una grave pérdida moral. Este sacrificio se suele enfocar como un mal que la decisión no pudo evitar.

4) La solución al conflicto es particularista: es la solución para "ese" caso puntual y no hay garantías ni lógicas ni epistémicas de que tal solución pueda universalizarse o generalizarse. 
De acuerdo con las características 1) a 4) hay situaciones de conflicto normativo que no tienen respuesta correcta dado que no es posible aplicar al mismo tiempo las dos demandas en conflicto; una de ellas será sacrificada generando pérdida moral (Greenspan, 1995, cap. 2) y la solución tiende a ser fuertemente particularista. Si aplicamos este cuadro del pesimista a los derechos humanos, la tesis sería que, frente a conflictos trágicos entre derechos, la respuesta no puede ser correcta ya que dejará pérdida moral. Lorenzo Zucca (2007) ha defendido justamente esta tesitura sosteniendo que hay casos trágicos donde no es posible solución correcta para lo que él denomina "dilemas constitucionales", es decir, para ciertos conflictos entre derechos humanos contemplados en una constitución. En estos casos según Zucca tenemos que admitir que un derecho que consideramos valioso ha debido sacrificarse y cuenta como pérdida o fuga moral. Algo semejante sostiene David Martínez Zorrilla (2007) cuando reflexiona que un juez, puesto a decidir un dilema producido entre derechos constitucionales, tendrá "discreción" para resolver ya que la respuesta al conflicto se halla “indeterminada" por razones que obedecen a las características 1) a 3) que, según señalamos más arriba, caracterizan a los dilemas en general. Guillermo Lariguet (2008; 2011), por su parte, ha sostenido que si aceptamos la posibilidad conceptual y empírica de fenómenos de conflicto trágico, se debería admitir la idea de sacrificios inevitables.

Ahora bien, normalmente, lo que se le critica a los que de un modo u otro enarbolan la categoría de conflicto trágico, es que esta clase de conflictos no existen, que son elucubraciones de ficción sin ninguna sustancia real. Las razones para este tipo de crítica son diferentes. A veces son razones de orden lógico para sostener que aceptar conflictos así controvierte principios de consistencia deóntica de la lógica de normas. Otras, que aceptar conflictos así sienta un pesimismo que corrompe una mirada esperanzada sobre el mundo. Y, finalmente, que dar la entrada a estos conflictos, supondría minar las bases de aquellas teorías morales ocupadas en servir de guía para resolver nuestros conflictos y disolver nuestras perplejidades. En contra de estas críticas pensamos que se puede encontrar una gran cantidad de ejemplos de dilemas reales y potenciales que hacen necesario revisar críticamente la fe irrestricta que la concepción ilustrada que hemos llamado "optimista" tiene en la Razón. Al respecto, piénsese, por ejemplo, en el conflicto que puede producirse entre el derecho a manifestarse públicamente y el derecho al libre tránsito. No siempre es posible aplicar ambos derechos a la vez. En ciertas ocasiones no hay más remedio que sacrificar uno de ellos, pese a que el derecho sacrificado era tan valioso como el que fue aplicado. Parece que este tipo de conflicto, si admitimos su existencia, pone en una encerrona a nuestros jueces, pues, hagan lo 
que hagan, decidan lo que decidan, no podrán evitar sacrificar un derecho igualmente exigible.

Un ejemplo de conflicto latentemente potencial en el mundo es el que ha sido expuesto por Amartya Sen (2011). El ejemplo parte de la existencia de tres niños que intentan resolver qué hacer con una flauta. Uno reclama la flauta bajo el argumento de que él es el único que la sabe tocar. El otro, la reclama bajo el argumento, de que él es tan pobre que sería el único juguete que podría tener. El tercero, reclama la flauta porque él fue quien la fabricó. Sen dice, muy plausiblemente, que si escucháramos cada uno de los reclamos por separado, pensaríamos que cada uno de ellos merece la flauta. Sin embargo, el mundo no es así. Quien escuche los tres reclamos y tenga la obligación institucional de decidir (un juez), sabrá que decida lo que decida afectará los derechos de alguno de los niños. Es, precisamente, frente a esta clase de conflictos que los optimistas sostienen la posibilidad de dar una respuesta correcta. Con lo cual, la balanza entre optimistas y pesimistas parece estar en una suerte de virtual empate filosófico.

Puestas así las cosas, parece que la oscilación entre el optimismo y pesimismo, tal como fueron caracterizados, nos deja frente a un dilema teórico: aceptar las premisas de una postura nos obliga a rechazar las premisas de la otra. Vamos a intentar poner remedio a este dilema esbozando, a continuación, los rasgos de una postura intermedia.

\section{La postura intermedia}

Como lo hemos indicado en la introducción, en este trabajo nos decantamos por una postura intermedia entre los dos extremos posturales que acabamos de presentar. Esta predilección por una postura intermedia no obedece a un celo por la medianía o por la timidez filosófica. Consideramos que ambos extremos (el optimismo y el pesimismo) captan ciertas verdades conceptuales sobre la importancia de los derechos humanos como categoría moral. Sin embargo, en el vigor de las posiciones se exacerban o distorsionan las cosas. Esta tensión entre posturas es fuente de una peculiar angustia filosófica pues nos sentimos tironeados entre verdades conceptuales sobre nuestros derechos; verdades presumiblemente incompatibles. Creemos que una terapia adecuada para esta angustia necesita imponer un cierto orden conceptual mediante una suerte de "corrección mutua" o, si se nos da licencia para usar con deliberada amplitud un término favorito de John Rawls, ejercer cierto 
"equilibrio reflexivo" entre ambas posturas, a fin de obtener como resultado final una concepción coherente y verdadera sobre los derechos que nos libere de la angustia de las tensiones. A este punto es preciso, entonces, recuperar todas las tesis que enunciamos en la introducción a fin de explicarlas con un poco de detalle. Se impone, por tanto, una forzosa reiteración. Las tesis eran las siguientes:

a) Como postulado a priori vamos a sostener que los derechos humanos son piezas maestras de logros de una reflexión moral madura. La naturaleza última de los derechos humanos es el resultado de una comprensión de moralidad. Esto sea dicho con la salvedad de que admitimos que los derechos positivizados a niveles constitucionales presuponen una complejidad sistémica mayor. La incorporación de derechos a materiales jurídicos exigirían, algo que no haremos aquí, una consideración pormenorizada de cómo inciden en el razonamiento práctico, por ejemplo de operadores del derecho como los jueces, la dimensión institucional del derecho y su naturaleza autoritativa. A esto se añade otro dato de enorme complejidad y dinamismo en el que no nos inmiscuiremos aquí y que tiene que ver con la internacionalización de los derechos humanos. Una reflexión de un Law of People y sus complejos mecanismos, aún en discusión y cambio, requieren desde luego un ensayo independiente y específico.

Análisis de a): En nuestra opinión, la etiología y gramática justificacional profunda de los derechos humanos se imbrica con la moralidad, concretamente con la moralidad política. Tales derechos son el logro exquisito de siglos de reflexión moral tanto individual como colectiva, algo así como la evolución del espíritu, diríamos en espíritu hegeliano. Los derechos, por tanto, son síntoma de madurez moral. Tal madurez debería converger en algo así como un sistema universal de derechos humanos. Sin embargo, no se nos escapan las réplicas de tipo escéptico y relativista que puede experimentar esta afirmación. Sin duda, una defensa consistente de los derechos humanos debe presuponer algún tipo de objetivismo moral y de horizonte de universalidad que contrarreste, ante todo, posturas escépticas o relativistas. Aquí daremos por buena la posibilidad de una convergencia universal y objetiva final. Esto no significa que las posturas escépticas no merezcan un adecuado ejercicio de respuesta. Pero aquí, al efecto conceptual y argumentativo de nuestro trabajo, consideraremos plausible la aspiración universal de la que hablamos. Es verdad que las culturas, de facto, pueden diferenciarse, pero esto no es un argumento ni conceptual ni normativo decisivo, para sostener la imposibilidad conceptual de una categoría universal y objetiva y tampoco para 
desestimar que a la larga fuera posible una convergencia final sobre los catálogos de derechos humanos y sobre sus fuentes de fundamentación.

De todas maneras, conviene transitar más lentamente el tipo de horizonte universal que tenemos en mente. Las críticas que tradicionalmente se le han hecho al universalismo de tipo ilustrado, universalismo que subyace a la posición que denominamos "optimista", son las siguientes: i) que se trata de una universalidad falsa pues está perfilada bajo las grandes narrativas (diría un seguidor de Lyotard) tramadas desde y para Occidente; ii) que los sujetos que forman la tela de dicha universalidad son vistos como incorpóreos y no como cuerpos incrustados en una cultura; iii) que es una versión ahistoricista que no tiene en cuenta los vaivenes históricos y las narrativas locales de cada cultura; iv) que es una imposición totalitaria sobre otras concepciones divergentes dentro y fuera de Occidente.

Creemos que hay cierto grano de verdad en las críticas que acabamos de articular. Sin embargo, si las mismas se radicalizan sin contrapesos conceptuales, terminaríamos en el otro extremo: lo que llamamos la postura "pesimista". Un antídoto para estos extremos se encuentra, en nuestra opinión y nuevamente, en una reconstrucción "intermedia" como la que queremos defender. A este respecto creemos que no estamos solos y que existen distintas vías filosóficas que se podrían ensayar intentando resumir en un todo coherente la síntesis de ideas contrapuestas entre dichas posturas extremas. Tenemos la impresión de que un "universalismo moderado o sensato", con el que nos sentimos cómodos, podría sentirse alineado con parientes próximos. Aquí mencionaremos a título de ejemplo y en forma sumaria tres de estos parientes. Por ejemplo, se podría pensar que, dentro de la misma evolución del pensamiento liberal, John Rawls (2001) ha rumiado, en términos de una "teoría no-ideal", en cómo encontrar un "derecho de gentes" tramado de tal forma que permita tener un paraguas conceptual que cubra a sociedades diferentes (pensemos, por ejemplo una sociedad americana y una iraní); para ello, hay que desprenderse de un concepto más estricto de sociedad democrática para abrazar un concepto más general de sociedad "decente" que permita evaluar el desempeño humanitario o no de distintas culturas. (Margalit, 2010) Otra es la postura de Seyla Benhabib (2006, pp. 19-20) consistente en defender un "universalismo interactivo postmetafisico" que, a la par de reconocer el valor de una razón dialógica universalista, no cae en la tentación de defender un universalismo puramente occidental, a-histórico, que recaiga en sujetos incorpóreos que carecen de narrativa, de historia y de pertenencia a comunidades de mayor o menor extensión geográfica y cultural. La otra postura podría ligarse con el pensamiento post-abismal de Boaventura de Sousa Santos (2010, pp. 87-99) que, en vez, de 
proponer un universalismo rígido que encorsete de manera tormentosa distintas versiones culturales de los derechos humanos recoja la necesidad de una "herméneutica diatópica", esto es, de una interpretación de topoi de diferentes culturas a fin de buscar un diálogo inter y transcultural que permita solapar aquellos aspectos comunes que todas las culturas comparten en un concepto focal como el dignidad humana.

Sin dudas, que nuestra defensa de un universalismo moderado o sensato necesita de algo más que una sinopsis de los rasgos muy generales que podría compartir con parientes próximos; parientes que, no obstante su familiaridad en algunas tesis muy generales, tienen rasgos de carácter o personalidad filosófica bien diferenciables. Pero acaso nuestra pintura baste a los efectos de presentación de este trabajo conjunto. Motivo por el cual, el presente ensayo debería evaluarse en términos de la constitución de un primer paso dentro de un programa de investigación más ambicioso que detalle en forma completa los rasgos de una postura universalista sensata o moderada.

Ahora bien, todo lo dicho hasta ahora no supone desconocer otro detalle que no carece de importancia. Nos referimos a los complejos entresijos normativos, conceptuales e institucionales de los derechos constitucionales nacionales y del derecho internacional en tanto órdenes normativos específicos que van recogiendo paulatinamente derechos humanos. Sólo estamos afirmando que la etiología y gramática de los derechos es del orden de la moralidad política; no estamos alegando que tales derechos no entren en maquinarias complejas de decisión que deban considerar factores jurídicos específicos, sea de órdenes domésticos, sea de un orden internacional o global. Pero esto, como hemos aclarado, es motivo para una serie de trabajos independientes sobre el derecho constitucional y el derecho internacional. Aun así, en ambos casos, el constitucional y el internacional, la tesis sigue siendo la misma: la naturaleza moral de los derechos humanos; lo cual exige, en términos de razonamiento práctico, que al menos una de las premisas de ese hipotético razonamiento, tenga que ver con la propuesta de lo que consideremos la mejor teoría normativa moral para el caso de que se trate. Un razonamiento conclusivo de un caso de derechos humanos requiere de una argumentación que a la larga o a la corta, se entrometa conscientemente con una discusión y fundamentación de teoría moral. Dicha interposición de una teoría, normativa para mayores datos, servirá como fuente justificatoria de las premisas normativas con que en dicho razonamiento pretendemos arribar a una conclusión práctica determinada. Pero aquí no termina la historia, pues aun quedará pendiente la pregunta sobre el carácter de dicho razonamiento práctico. Una postura optimista, de nuevo, verá que tal razonamiento es de 
carácter universalista pues las conclusiones prácticas alcanzadas son generales o universales, a la par que un pesimista podría auspiciar una posición "particularista fuerte" según la cual no hay garantías ni lógicas ni epistémicas de que la conclusión pueda universalizarse. Nuevamente, consideramos que ambas posturas son extremas y aunque captan problemas nucleares sobre la naturaleza del razonamiento práctico, caen en excesos que es necesario corregir. No abogamos, en efecto, por un universalismo rigorista o totalitario que no contemple excepciones o sensibilidad por el contexto en el que surge y se desarrolla un conflicto que involucra derechos. Pero tampoco nos cuadra un particularismo tan fuerte que se vuelva reluctante a la posibilidad y necesidad de reconstruir al menos algunos patrones subyacentes generalizables a partir de una sucesión de diversos razonamientos prácticos que tienden a resolver conflictos. La verdad, nuevamente, está en el medio. Necesitamos defender, por esto, un razonamiento que para casos paradigmáticos y sobre los que es posible aglutinar mayor densidad de diálogo pacífico y acuerdo, cierto universalismo latente en las conclusiones prácticas alcanzadas. En cambio, para los casos más ríspidos que suscitan mayor desacuerdo o entorpecen el diálogo pacífico, es preciso un mayor esfuerzo de comprensión contextual, de sensibilidad por las peculiaridades del conflicto, de sus agentes y de su entorno. Esto probablemente requiera adosar al tema del razonamiento la discusión de si no son necesarias virtudes epistémicas y morales que ayuden a agudizar una mirada sensible por el contexto. Pero, sin embargo, sensibilidad contextual no es igual a particularismo fuerte. Un esfuerzo ulterior de ascenso semántico (para parafrasear una categoría quineana) debería y podría conducir a identificar patrones de razonamiento que van más allá de un caso puntual y donde las conclusiones prácticas no son milagros episódicos o rapsódicos sino que pueden oficiar de guía para resolver conflictos futuros. Esto no significa decir que haya algo así como una garantía de hierro de que se pueden encontrar estos patrones "a la vuelta de la esquina". Pero pretender tal cosa es caer en la necesidad de una "certeza cartesiana" inasequible. En resumen: nuestra postura defendería lo que Thomas Nagel denomina un universalismo "sensato o no totalitario" que admite la necesidad de juicios contextuales pero que considera que, ulteriores esfuerzos, pueden ayudar a identificar patrones generalizables; generalizables sí, pero a la vez, falibles o revisables. (Nagel, 2000, p. 225) De esta forma se podría ir consolidando un programa de investigación que aglutine lo mejor de un universalismo y particularismo duro. (González de la Vega, 2013)

b) Que los derechos humanos, qua piezas morales, se integran, en nuestra perspectiva, a una versión del razonamiento práctico unitaria y no fragmentaria. Esto no 
significa moralizar porque sí cualquier dominio práctico. El riesgo de esto sería lo que se ha popularizado con el nombre de un "infierno moral”. Al contrario, en nuestra visión, el razonamiento práctico orbita sobre distintos dominios prácticos (estéticos, religiosos, políticos, jurídicos) lo cual no significa diluir los criterios de identidad y solución de conflictos de cada dominio. Antes bien, la idea de que la razón práctica se integra de distintos dominios y que no todos son de índole moral, que estos dominios son, por ejemplo, el estético o religioso, convalida tácitamente el reconocimiento de una relativa autonomía de dichos dominios. Esta autonomía relativa implica que si hubiera un conflicto, por caso, a nivel de normas estéticas, el propio dominio contaría, en principio, con criterios de solución. Distinto es el caso si el conflicto estético tiene un punto de contacto fuerte y evidente con el dominio moral; porque, en dicho, caso por razones pre-asumidas de unidad del razonamiento práctico, deberían aplicarse criterios morales.

Análisis de b): Para defender la primacía práctica de los derechos humanos sobre otras piezas normativas juzgamos que un paso conceptual ineludible es presuponer a priori una forma de unidad del razonamiento práctico. Lejos de lo que alguna variante fragmentarista del razonamiento práctico pudiese sostener, creemos que asumir como postulado de trabajo la unidad del razonamiento práctico no implica negar que existan conflictos entre elementos que pertenecen a un mismo dominio (conflictos intrasistémicos) o entre elementos que pertenezcan a distintos dominios (conflictos intersistémicos). En nuestros términos, la primacía significa que los derechos humanos, como piezas de ingeniería moral madura, priman sobre elementos normativos de otros dominios. Esto por la asunción, también a priori, de la predominancia de la moralidad sobre otros dominios. Pero la expresión "otros dominios" es elocuentemente significativa: presupone que admitimos la identidad y autonomía de dominios que no son morales. Así, toto genere, hablamos de un dominio estético, de uno religioso, de uno jurídico, etc. Decir "un" dominio, es sin duda una manear simplificadora de hablar pues tales dominios, y lo mismo ocurre con la moral, son objeto de disputa entre teorías rivales que compiten por presentar bajo su mejor aspecto y justificación a cada dominio. Pero más allá de esta cautela semántica, digamos que la idea de "otros dominios" que son autónomos muestra una significativa sensibilidad por el pluralismo de dominios y valores que no es lo mismo que por la "fragmentación" del razonamiento práctico. En efecto, admitimos la tesis general de que hay valores plurales y dominios objetivos, lo cual no es analíticamente equivalente a admitir fragmentación. Por "fragmentación” o postura "fragmentarista" aquí entendemos la idea de que hay múltiples dominios prácticos cada uno 
librado a su propia criteriología. Esta postura nos parece contra intuitiva por dos motivos. El primero es que existen casos que evidencian fuertemente la importancia del "toque moral" o de la necesidad del análisis moral, por más que se trate de un dominio no-moral como el estético, el jurídico o el político. El segundo es que la admisión tácita o expresa de conflictos entre piezas de distintos dominios presupone que tales dominios deben poder relacionarse o conectarse de diversas maneras. Si cada dominio fuese absolutamente autónomo no habría estrictamente hablando conflictos sino simples "choques de planetas". Por lo pronto, vamos a suponer aquí que cada dominio práctico (moral, estético, político, jurídico) puede referir a dos clases diferenciables de sistema normativo. Un sistema básico que está compuesto por creencias, criterios o normas folk y un sistema justificante o último que está compuesto por creencias, criterios o normas de mayor grado de reflexividad que las del sistema básico. A menudo nos manejamos, sin ser siempre conscientes de ello, con las piezas de un sistema básico, pero cuando se produce una situación irritativa, de determinada situación recalcitrante, o lisa y llanamente un conflicto de creencias o intuiciones, puede intervenir el sistema justificante para determinar si mantenemos el criterio del sistema básico o si lo desplazamos por una razón de orden superior dictaminada por el sistema justificante. Veamos un ejemplo tomado del relato de Manuel Vicent (1983; para un análisis Garzón Valdés, 1992) modificado para el presente ensayo; nos referimos a "No pongas tus sucias manos sobre Mozart". Supongamos que nuestro sistema básico es muy "tolerante" con un hijo nuestro que trae sus amigotes a casa frecuentemente; estos amigotes ensucian el baño, dejan los platos sucios y nos toman las mejores botellas de vino. Pero un día, un mal día, uno de los amigotes con sus sucias manazas quiere tocar un disco con la música selecta de Mozart tocada por la Filarmónica de Viena. Allí nuestro sistema básico es exasperado y gritamos sin poder impedirlo: “¡no pongas tus sucias manos sobre Mozart”! Aquí una razón del sistema justificante de este padre angustiado opera como desplazante de las razones básicas que teníamos para tolerar a nuestro hijo y sus amigotes. El límite fue Mozart. En el ejemplo que acabamos de presentar el conflicto podría suscitarse a nivel de un mismo dominio, supongamos uno vinculado al orden estético. Dicho dominio, cuenta con su relativa autonomía, lo cual significa que tiene sus propios criterios identitarios así como su criteriología para hacer frente a casos como el del disco de Mozart.

Cambiemos ahora la tónica de los ejemplos. Supongamos que un artista toma un perro callejero malherido y así, sin curarlo, lo fija a una madera, y bajo unas luces dicroicas lo expone al público, en la última Bienal de San Pablo, a título de "la belleza de la agonía" o un 
título parecido. Dicha exposición, probablemente suscitaría acaloradas discusiones no sólo acerca de si está moralmente bien lo que hizo el artista sino acerca de si su exposición cuenta como obra de arte. Nuestra intuición es que aquí no se trata de una discusión que solo podamos referir al dominio de la estética sino que involucra un problema moral, a saber, si es lícito perpetuar el sufrimiento de un animal, o de un ser sintiente, para sacrificarlo al altar del "arte". Nuestra intuición moral es que las cosas están mal planteadas desde el vamos. Aquí no hay que sacrificar nada en pos del altar del "arte". Lo que hace este artista no es arte, pero con seguridad presupone una forma abierta de inmoralidad que muestra la punta tenebrosa de lo que podría ser un carácter depravado. Una "buena obra de arte" no sería buena por satisfacer solo criterios estéticos sino también morales. Por supuesto que podemos tener desacuerdos rivales en ambos planos: el estético y el moral. Por caso, a un hombre sensible por el arte y su historia, el orinal de Duchamp podría parecerle una porquería que sólo en nombre del esnobismo llamaríamos arte. Otra teoría rival en cambio podría sostener lo contrario. En el terreno moral, por su parte, podríamos también tener desacuerdos. Por ejemplo, el Cristo planchado sobre un avión de guerra del pintor fallecido León Ferrari, para ciertos ultra católicos puede parecer una inmoralidad. Pero "ser" y "parecer" no son la misma cosa. Deberíamos presuponer una base objetiva para nuestras discusiones; al menos de objetividad qua argumentabilidad. Debemos, en efecto, dar los mejores argumentos (empíricos, conceptuales, normativos, etc,) para nuestras posturas interpretativas. Además, que haya desacuerdos no es prueba contundente de que la objetividad qua argumentabilidad es imposible; más bien, la misma, es una demanda implícita en cualquier práctica en la que pretendemos discutir seriamente sobre nuestras diferencias. Si de lo que vamos a discutir es sobre moralidad o inmoralidad, un buen punto de inicio puede ser la teoría de Mill del principio de "no daño". Hasta donde alcanzamos a ver, la obra pictórica de León Ferrari no produce ningún daño palpable filosóficamente atendible, en cambio el perro, qua ser sintiente sí que es dañado con la conducta del artista que poníamos en el ejemplo. Toda esta argumentación va en la senda, entonces, de poner en evidencia que, cuando hay un problema que tiene un punto moral fuerte de contacto, como en el caso del ejemplo del perro, lo que tenemos que hacer es aplicar criterios morales que son prevalentes. Es más, en estos casos, no hay como se suele decir un poco superficialmente, algo así como el "balance" entre alternativas en conflicto, en este caso, entre normas morales y estéticas. Sino más bien que reconocemos la prioridad de las primeras sobre las segundas. Si las segundas, en cambio, no 
generan un conflicto con el dominio moral, por ser indiferentes, entonces, se aplica autónomamente dicho dominio sin necesidad de la intervención de la moral.

c) Que entre los derechos humanos y otras piezas normativas, por ejemplo objetivos colectivos o prudenciales, tienen primacía prima facie los derechos. Para revertir la prioridad, son necesarios fuertes argumentos políticos y morales objetivos que justifiquen un sacrificio razonable y temporalmente delimitado de los derechos.

Análisis de c): Esta tesis es prioritariamente de estirpe liberal deontológica. Un postulado de las teorías liberales es la prioridad de los derechos humanos sobre otras piezas normativas, por ejemplo, los llamados objetivos colectivos, esto es, aquellos que involucran razonamientos de maximización de utilidades o agregación de preferencias. Esta opción a priori por el liberalismo no la vamos a fundamentar aquí, pero sí queremos dejar en claro que la misma no repele la fuerza normativa y la ejecutoriedad judicial, en principio, de los llamados derechos "sociales". Con independencia de la compleja y larga discusión que existe al respecto de estos derechos, consideramos que los mismos, finalmente, se satisfacen en individuos. Nuestra intuición es que un estado justo no es sólo aquél en el que satisfacemos derechos humanos individuales (libertad de religión, de asociación, de prensa, de expresión, de movimiento, de consciencia, etc.) sino aquel estado donde los más desfavorecidos o desaventajados por condiciones que no estaban bajo su control ni fueron elegidas por ellos, deben ser compensados. Parte de nuestra intuición se fortalece si reconocemos, en principio, la fuerza normativa y la ejecutoriedad de los llamados derechos sociales; más allá de si, desde un punto de vista ontológico-conceptual, los mismos se terminen aplicando a individuos.

Ahora bien, volvamos a la tesis de primacía de los derechos humanos -típicamente los llamados derechos "individuales"- sobre los objetivos colectivos del tipo "es necesario bajar la tasa de criminalidad en Río de Janeiro", es "menester elevar los estándares de control ambiental en la cuenca del Río de la Plata" o es "perentorio maximizar las condiciones de seguridad interior de los Estados Unidos de América”. Ante todo digamos que el trazado y ejecución de objetivos colectivos no siempre arrastra, por una suerte de imperiosa necesidad lógica, el sacrificio de derechos individuales. Sin embargo, aquí vamos a concentrarnos, por un momento, en casos más complejos que generan un potencial conflicto con los derechos humanos o, al menos, suscitan discusiones teóricas y prácticas. Éste es el caso, precisamente, del último ejemplo, el referido a las condiciones de seguridad. Después del 11 de septiembre y de la destrucción de las "torres gemelas" el mundo de muchos derechos nacionales fue sacudido por una serie de modificaciones normativas tendentes a maximizar condiciones de ethic@- Florianópolis, Santa Catarina, Brasil, v.13, n.2, p.252-282, jul./dez., 2014. 
seguridad. En este punto, se admitieron cosas como por ejemplo, espiar comunicaciones, abrir correspondencia o detener a sospechosos sin previa orden judicial. Incluso se activó la posibilidad de una orden presidencial de "derribo" de aviones que presumiblemente van a impactar contra un objetivo civil.

Si hablamos en términos de la jerga del famoso filósofo Herbert Hart, podríamos aventurar que la textura de la regla de reconocimiento de nuestros sistemas jurídicos ha sido trastocada considerablemente y ahora estamos frente a una regla que acepta como "válidos" criterios normativos como los que acabamos de ejemplificar. No hace falta mucha perspicacia, para advertir que dichos criterios o enmiendas normativas involucran un sacrificio de derechos y garantías individuales; derechos y garantías que eran, hasta el momento, y para parafrasear a Ronald Dworkin, nuestras "cartas morales de triunfo" frente a decisiones mayoritarias que pueden ser irracionales o arbitrarias.

Herbert Hart siempre sostuvo que la existencia de una regla de reconocimiento involucraba un conjunto complejo de creencias de "aceptación". La masiva incorporación de elementos como los que ejemplificamos arriba, podrían sugerir no sólo el sacrificio de derechos, desconsiderando su primacía, sino también involucrar, como ha dicho Alberto Puppo (2013, pp. 19-38), una suerte de aceptantes "patológicos" de este nuevo derecho post11 de septiembre.

No desconocemos que el juego de la política doméstica y de la política internacional tiene sus propias peculiaridades. Esas que llevaron al punto de los filósofos á la Maquiavelo a admitir la imposibilidad conceptual de "ensuciarse las manos". Sin embargo, creemos que una discusión más profunda todavía debe ser librada. Los argumentos para sacrificar derechos deberían ser totalmente abiertos, explícitos y fundarse en razones no sólo empíricas (de peligro cierto inminente) sino también normativas (es decir bajo qué condiciones estrictas se podrían desconsiderar, al menos parcialmente, ciertos derechos). Además, estos sacrificios deberían guardar una relación de "proporcionalidad" con la entidad objetiva del mal que se pretende conjurar y deberían ser establecidos de manera limitada. De lo contrario, por una pendiente resbaladiza podríamos perder nuestros sistemas de derechos.

d) Que entre los propios derechos humanos puede haber conflictos. Como partimos de la idea a priori de que tales derechos gozan de mismo rango axiológico, entonces estamos frente a un dilema moral.

Análisis de d): En efecto, aceptamos que existen indicadores fenomenológicos de que puede haber conflictos entre los propios derechos humanos. Si partimos de la asunción de 
que todos en principio gozan del mismo estatus axiológico, entonces los conflictos podrían derivar en dilemas morales. Ellos podrían activarse si para satisfacer una demanda basada en un derecho humano tenemos que desconocer o sacrificar la demanda que se basa en otro derecho. Nuestros ordenamientos políticos y nuestras prácticas constitucionales muestran que tales dilemas no son conceptual ni empíricamente imposibles. Esta asunción de dilemas, sin embargo, nos pone un poco cerca del pesimismo, sobre todo en la descripción del concepto de “conflicto trágico" que dimos - párrafos atrás- en términos de la condición 1). Es decir, incompatibilidad normativa trasuntada en la imposibilidad de satisfacción conjunta de dos demandas igualmente valiosas pero incompatibles. Sin embargo, nuestra posición no es pesimista en un sentido pleno. Ello sería así si aceptásemos de manera absolutamente irrestricta las condiciones definitorias 2) y 3), esto, es, que las alternativas de un conflicto son mutuamente inderrotables y/o incomparables, o bien que hay un sacrificio lamentable o pérdida moral grave inevitable.

No estamos completamente seguros de que 2) y 3) no puedan presentarse contingentemente. Pero sí creemos que una mirada atenta a nuestras prácticas no parece registrar muchos o abundantes casos así. Nuestros sistemas político jurídicos, por una parte, y la mayoría de nuestras teorías morales, inclusive de las que son amigables con la posibilidad de dilemas, no necesariamente reculan frente a los mismos. De la definición de conflicto trágico dada en 1) no se sigue necesariamente la completa derrota de las teorías morales o de los sistemas jurídicos, según el ámbito en el que se planteen los conflictos. Decir lo contrario supondría asumir, en forma no fundamentada, algo así como un fatum mahometanum conforme al cual no importa lo que hagamos, tales conflictos son siempre irresolubles racionalmente o nos condenan a graves pérdidas morales. Insistimos: no estamos en condiciones de sentar el truísmo de que tales conflictos son conceptualmente imposibles, pero sí que podemos aseverar que nuestras prácticas, nuestros sistemas jurídicos y nuestras teorías morales, no claudican en la búsqueda, refinamiento y discusión de complejos y amplios criterios de resolución "racional".

e) Sostendremos que los dilemas morales no pueden evitarnos a priori una investigación racional. Los pasos de dicha investigación deberían conducir a bucear imaginativamente en un elenco de respuestas. Las mismas, por orden de plausibilidad, irían en el siguiente orden. En primer lugar se debería tratar de escapar entre los cuernos del dilema, buscando satisfacer conjuntamente ambos derechos, lo cual podría requerir, a veces, y cuando ello resultara posible, en una satisfacción de compromiso entre ambos derechos. En segundo 
lugar, si lo anterior no fuera posible, buscar una solución lo menos lesiva posible para los involucrados, minimizando los males. En tercer lugar, si un sacrificio irreparable fuese inevitable, entonces generar compromisos para mejorar a futuro nuestras creencias, prácticas, instituciones, etc, a fin de evitar o morigerar el impacto de conflictos futuros.

Análisis de e): En efecto, de un modo u otro, y mutatis mutandis, nuestras teorías morales y nuestros sistemas jurídicos, particularmente los constitucionales, suelen ofrecer una amplia gama o paleta de criterios de solución. Mencionemos sólo algunos ejemplos muy variados. Así, por caso, la oferta de meta principios que permitan jerarquizar derechos como es el caso del principio "pro homine", o la tesis de que sólo una es la obligación finalmente correcta o decisiva que cuenta como un obrar moralmente correcto en un caso, o la tesis de que es posible especificar qué derechos se aplican en forma preponderante, o las conocidas teorías de balances o ponderaciones objetivas entre derechos en conflicto. Por supuesto, no se nos escapa que los criterios son muchos más, que cada uno podría ser refinado exquisitamente con otras distinciones y que cada uno podría suscitar desacuerdos filosóficos de diversa índole. Sin embargo, la breve lista muestra que las teorías morales y los sistemas jurídicos no claudican en una derrota absorbida por un fatum mahometanum. Los criterios de solución intentan transitar los siguientes paso que mencionamos al final de e), a saber: Primero intentar escapar entre los cuernos, mostrando un camino que suponga el intento de satisfacer ambos derechos si no en su totalidad, al menos en una suerte de vía de "compromiso". Se trataría de un tipo de compromiso que demanda, por ejemplo, una cesión del terreno de cada derecho a fin de encontrar un lugar común en el que ambos mínimamente puedan converger o satisfacerse. Básicamente una fuerte presión psíquica y normativa por la coherencia o la armonía nos puja a buscar formas racionalmente comunicables y argumentables que sirvan para fundamentar estas salidas de compromiso o conciliatorias entre derechos en pugna. Aquí serán particularmente importantes teorías de la coherencia práctica, del equilibrio reflexivo, de las virtudes epistémicas y morales de los agentes equipados de manera aretaica para buscar las soluciones más imaginativas y que a la vez calcen con nuestras prácticas, etc. El segundo paso será de menor ambición. Si no fuera posible 1) entonces habrá que buscar categorías, criterios, etc, que nos permitan decantarnos por el "mal menor", una tesis ampliamente recorrida desde casos como la "tabla de Carnéades", el "estado de necesidad", la "balsa de la Medusa", o el caso retratado por Lon Fuller en los "exploradores de cavernas". La salida menos lesiva para los derechos en conflicto es la que contará como la racionalmente menos mala. 
Y, por último, si 1) y 2) fracasaran, estaríamos en los bordes del terreno mismo del conflicto trágico tal como lo pintan conceptualmente las condiciones definitorias que ya dimos. En este caso, sin embargo, no cabría un irredimible pesimismo como el que destilan las páginas de Pío Baroja o la posición de Unamuno de que al final no hay esperanza alguna sino derrota inevitable. Puede ser, como hemos dicho, que existen conflictos genuinamente trágicos en este sentido, es decir, conflictos sin happy endings, pero sin embargo de aquí tampoco se sigue un pesimismo absoluto. Podemos aprender de nuestros errores, de nuestros fracasos, y de nuestros presentes límites racionales y emocionales. Todavía más: podemos conquistar futuros triunfos o al menos no sufrir derrotas tan profundas. La enseñanza de lo trágico no es que debemos sentarnos a esperar lo peor sino que debemos introducir cambios en algunas de nuestras creencias, en ciertas parcelas de nuestras prácticas, en determinadas concepciones de los valores, en partes de nuestros sistemas jurídicos y debemos seguir refinando nuestras teorías morales (Lariguet, 2009).

A lo mejor, en el futuro, podamos estar mejor equipados para evitar algunos conflictos trágicos o conjurar sus efectos potencialmente deletéreos transitando los pasos 1) y 2) que detallamos anteriormente.

\section{Consideraciones finales}

La mayoría de los problemas que hemos presentado, así como las tesis que hemos defendido, han sido ya debidamente explicitadas en el cuerpo de nuestro artículo. No obstante, no está de más efectuar un somero repaso de las principales cuestiones tratadas en el texto. A modo de recuento de algunas de las principales tesis expuestas, comenzaremos por recordar que nuestro eje conceptual estuvo puesto en la categoría de los "derechos humanos", entendida en términos de asumir su supremacía práctica. Nuestro mapa teórico indicó que sobre la mentada supremacía de los derechos humanos existen dos grandes familias de concepciones rivales. Por un lado una concepción optimista, por el otro, una concepción pesimista. Mientras la primera exalta las capacidades normativas omnímodas de los derechos humanos para resolver todas nuestras acuciantes contiendas prácticas sustantivas, la segunda fortalece diversas especies de escepticismo, uno más radical que el otro. Supusimos, a título de intuición si se quiere pre-analítica, que ambas concepciones, defendidas con tanta vehemencia, deben tener un grano de verdad. Sin embargo, como la conjunción de ambos 
conjuntos de concepciones llevan a un atolladero lógico, propusimos que la verdad, como suele ocurrir a menudo, está en el medio de estos dos extremos. Tal verdad es recogida por la concepción que acá defendimos bajo el nombre de "moderada". La misma presupone un trabajo de equilibrio reflexivo entre posturas extremas buscando extraer la pepita de verdad y razonabilidad moral y política que encierra la categoría de los derechos humanos. A fin de esquematizar nuestra posición definimos oportunamente los rasgos conceptuales que la definen en forma clara. Vale la pena recordarlos de manera sintética ahora.

En primer lugar que los derechos humanos no son cualquier clase de categoría. Si bien se los emplea en forma a veces indiscriminada en distintos tipos de discurso efectuados con propósitos de presión o persuasión, no se puede olvidar que etiológicamente los derechos humanos forman parte de la gramática más profunda de nuestra moralidad madura o reflexiva. Fuimos advertidos, sin embargo, de los esperables ataques que esta visión puede experimentar de la mano de enfoques de tipo escéptico y/o relativista. A este punto, sostuvimos que un buen remedio para estos ataques está dado por la defensa de formas de universalismo sensato, como las que ejemplificamos, hechas las respectivas salvedades diferenciales, con base en autores como Rawls, Benhabib o Boaventura de Sousa Santos.

En segundo lugar, que como categoría moral los derechos humanos se vuelven inteligibles bajo una versión razonable de unidad del razonamiento práctico. Esto implica la aplicación de un orden de prioridad de elementos morales sobre otros elementos normativos no morales. Dejamos empero abierta una puerta para discutir casos en que no debe aplicar tal prioridad sino una idea más relajada como la de balance entre opciones contrapuestas.

En tercer lugar, como derivación de la vinculación entre las dos tesis anteriores, que la categoría central de nuestro presente objeto de análisis da sentido a la idea según la cual los derechos humanos tienen, como diría Ronald Dworkin en forma ya célebre, una "carta de triunfo" sobre otras piezas normativas tales como por ejemplo los objetivos colectivos. Al respecto, mantuvimos que el eventual sacrificio de los derechos humanos en aras de cumplimentar con un urgente objetivo, debía satisfacer serias restricciones normativas de temporalidad y razonabilidad bajo las cuales fuera plausible justificar tal sacrificio o desplazamiento.

Por último, reconocimos que algunos conflictos entre derechos humanos podían presentarse bajo la forma -un tanto terrorífica- de dilemas morales trágicos. Sobre este tema, indicamos que la presencia de tales situaciones podía enfrentarse desde tres perspectivas analíticamente diferenciables. La primera consistía en la más optimista idea de poder escapar 
entre los cuernos del dilema. La segunda, ante el fracaso de la primera, en la articulación de una eventual minimización de los males en juego. La tercera, en aceptar con humildad los límites de nuestras armazones intelectuales para resolver tales dilemas, sea escapando entre los cuernos, sea minimizando males. Empero, humildad no es igual a derrota absoluta. Argumentamos que la lección de los dilemas trágicos debería consistir, en buena medida, en tomarse en serio la tarea de modificar creencias, pautas de valor, juicios, instituciones, a fin de evitar que los mismos conflictos puedan presentarse a futuro o, al menos, buscar la forma de reducir el impacto de sus posibles efectos deletéreos en tal futuro. 


\section{Notas Explicativas}

${ }^{1}$ Estamos agradecidos con las sugerencias que nos hiciera uno de los árbitros anónimos del trabajo. Las mismas nos han ayudado a mejorar este artículo.

${ }^{2}$ CONICET, Centro de Investigaciones Jurídicas y Sociales, Universidad Nacional de Córdoba, Argentina. Email: gclariguet@gmail.com

${ }^{3}$ Universidad Nacional Autónoma de México. E-mail: renegonzalezdelavega@gmail.com

${ }^{4}$ En este sentido, los filósofos que sostienen esta línea de pensamiento presuponen una visión del razonamiento práctico conforme la cual el discurso moral tiene primacía sistémica sobre el discurso jurídico y el político. Otros autores, como por ejemplo Mouffe, 2009, cap. 4, verían negativamente esta forma de pensar. Sostendrían, por ejemplo, que la "moralización de la política" - vía el concepto de derechos humanos- pierde de vista la naturaleza adversarial y agonística de la lucha política.

${ }^{5}$ Por ejemplo, Bernard Williams (1993, p. 38) afirma que "algunas veces nos guía la idea de que el mejor de los mundos sería aquél en que la moralidad se respetara universalmente y todas las personas estuvieran dispuestas a avalarla; en realidad tenemos razones profundas y persistentes para agradecer que nuestro mundo no sea así”.

${ }^{6}$ Idem.

${ }^{7}$ Idem.

${ }^{8}$ Aquí hacemos una clara alusión a la tesis defendida por Ronald Dworkin.

${ }^{9}$ Parece ser que H. L. A. Hart tiene razón cuando afirma que las diferencias que existen entre doctrinas utilitaristas, al menos las clásicas, y otras de tipo deontologista, es que unas están basadas en un principio de maximización el cual se enfoca en aumentar el balance total de felicidad del mayor número de sujetos, mientras que las otras, se basan en un principio distributivo que da prioridad a la satisfacción de intereses básicos de cada individuo. Hart, op. cit., p. 182.

${ }^{10}$ Sobre el aporte de la literatura a la filosofía práctica en general y moral en especial puede verse Nussbaum, 2005. 


\section{Referencia Bibliografía}

Alexy, Robert. "On balancing and subsumption. A structural comparison, Ratio Juris, Vol. 16. 2003.

Atienza, Manuel. Introducción al Derecho, Fontamara, Doctrina Jurídica Contemporánea, México, 2008, pág. 149.

Benhabib, Seyla. El ser y el otro en la ética contemporánea. Feminismo, comunitarismo y posmodernismo. Traducción de Gabriel Zadunaisky, Barcelona, Gedisa, 2006, pp. 19-20.

Berlin, Isaiah. The Roots of Romanticism, The A. W. Mellon Lectures in the Fine Arts, The National Gallery of Art, Washington D.C., Bollingen Series XXXV:45, Princeton University Press, 1999, pp. 21-2.

Brudner, Alan. Constitutional Goods. Oxford University Press. 2007. p. 297 y ss.

Chang, Ruth. Incommensurability, Incomparability and Practical Reason, Harvard University Press. 1997.

De Sousa Santos, Boaventura. Para descolonizar Occidente. Más allá del pensamiento abismal. Buenos Aires, Prometeo Libros, UBA, CLACSO, 2010. pp.. 87-99.

Dworkin, Ronald. Justice for Hedgehogs, The Belknap Press of Harvard University Press, 2011, pp. 351 y 364.

Dworkin, Ronald. Los derechos en serio, Ariel, Barcelona, 2002, pág. 397.

Eskridge, William and Levinson, Sanford. "Antigone and Creon", en Eskrigde and Levinson Eds, Constitutional Stupidities, Constitutional Tragedies, NYU Press, 1998. pp. 248-256.

Garzón Valdés, Ernesto. "No pongas tus sucias manos sobre Mozart. Algunas consideraciones sobre el concepto de tolerancia". Estudios. Filosofia y Letras. En http://biblioteca.itam.mx/estudios/estudio/letras29/texto3/sec 1.html 1992

González de la Vega, René. Tolerance as a Moral Ideal in Contemporary Liberalism: A Conceptual and Justificatory Analysis, Tesis Doctoral, Universidad de Lovaina y Católica de Brusselas, 2013.

Greenspan, Patricia. Practical guilt: moral dilemmas, emotions, and social norms, Oxford University Press, 1995. Capítulo 2.

Griffin, James. On Human Rights, Oxford University Press, 2008, pág. 65.

Hart, H.L.A. "Utilitarianism and Natural Rights", Essays in Jurisprudente and Philosophy, Clarendon Press, Oxford, 1983, p. 182. 
Hart, H.L.A. American Jurisprudence Through English Eyes. The Nightmare and the Noble Dream, in Id., Essays inJurisprudence and Philosophy, Clarendon Press, Oxford, 2001. p. 132 y ss.

Laporta, Francisco. "Sobre el concepto de derechos humanos", Doxa. Cuadernos de Filosofía del Derecho, No. 4, Alicante, 1987, pág. 39.

Lariguet, Guillermo. 2009. "The concept of tragic conflict: between challenge and hope", Facing Tragedies, Hamilton, Neumaier, Schweiger y Sedmak (editors), Viena, Lit-Verlag.

Lariguet, Guillermo. Dilemas y conflictos trágicos. Una investigación conceptual. Prólogo de Manuel Atienza, Lima-Bogotá. Palestra-Temis. 2008.

Lariguet, Guillermo. Encrucijadas morales. Una aproximación a los dilemas y su impacto en el razonamiento práctico. Prólogo de René González de la Vega, Theoria Cum Praxi, Madrid, Plaza y Valdés. 2011.

MacIntyre, Alasdair. Tras la virtud. Traducción de Amelia Valcárcel. Barcelona. Critica. 1987.

Margalit, Avishai. La sociedad decente, Paidós, Madrid, 2010.

Martínez Zorrilla, David. Conflictos constitucionales, ponderación e indeterminación normativa. Marcial Pons, Madrid, 2007. p. 371.

McConnell, Terrance. “Moral Dilemmas”, Stanford Encyclopedia of Philosophy, 2010.

Mouffe, Chantal. En torno a lo político, FCE, México, Capítulo 4. 2009.

Nagel, Thomas. "Resistiendo a la teoría ética", Otras mentes. Ensayos críticos 1969-1994, Traducción Hugo Enrique Sánchez, Barcelona. Gedisa, 2000. p. 225.

Nino, Carlos. Ética y Derechos Humanos. Un ensayo de fundamentación, Astrea, Buenos Áires, 2005, p. 21 y ss.

Nussbaum, Martha. El conocimiento del amor. Ensayos sobre filosofía y literatura. Mínimo Tránsito, Madrid. 2005.

Post, Robert. "Tragedy and Constitutional Interpretation: California Civil Rights Initiative", en Eskrigde and Levinson Eds, Constitutional Stupidities, Constitutional Tragedies, NYU Press, 1998. pp. 217-225.

Puppo, Alberto, "Estado de excepción. Algunas consideraciones acerca de héroes garantistas y participantes patológicos", en González de la Vega, Lariguet, Guillermo (coord.), Problemas de Filosofía del Derecho. Nuevas Perspectivas, Temis, Colombia, 2013, pp. 1938.

Rawls, John. El derecho de gentes y una "revisión de la idea de razón pública”, Traducción de Hernando Valencia Villa, Madrid, Paidós. 2001.

Raz, Joseph. The Morality of Freedom, Clarendon Press, Oxford, 1986, pp. 193-4. 
Rogers, Edith R. "Sobre el pesimismo de Baroja", Hispania, Vol. 45, No. 4, (Dec., 1962), p. 671.

Sen, Amartya.. La idea de la justicia Traducción de Hernando Villa, Madrid. Taurus. 2011.

Sinnott-Armstrong, Walter. Moral Dilemmas, Oxford, Basil Blackwell, 1988. p. 20 y ss.

Todorov, Tzvetan. El jardín imperfecto. Luces y sombras del pensamiento humanista, Paidós, Madrid. 1999.

Vicent, Manuel, No pongas tus sucias manos sobre Mozart, Madrid, Debate, 1983.

Williams, Bernard. "Conflicto de Valores", en La fortuna moral, UNAM, México, 1993. p. 93.

Williams, Bernard. La Fortuna Moral. Ensayos filosóficos 1973-1980, IIF-UNAM, 1993, p. 38.

Zucca, Lorenzo. Constitutional Dilemmas. Conflicts of fundamental legal rights in Europe and USA, Oxford University Press. 2007. 